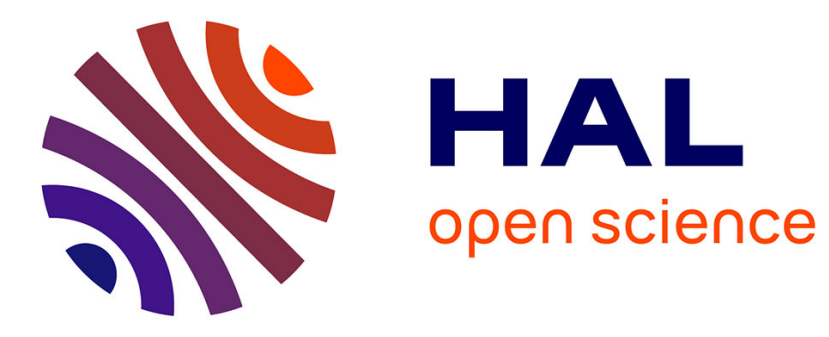

\title{
Modeling of an Ultrasonic Powder Transportation System
}

Razvan Chitic, Frédéric Giraud, Betty Lemaire-Semail, Richard Bearee, Monique Favre, Pascal Tierce, Jacky Jehanno

\section{To cite this version:}

Razvan Chitic, Frédéric Giraud, Betty Lemaire-Semail, Richard Bearee, Monique Favre, et al.. Modeling of an Ultrasonic Powder Transportation System. EPE 2013 - 15th Conference on Power Electronics and Applications, Sep 2013, Lille, France. pp.6, 10.1109/EPE.2013.6634662 . hal-03165119

\section{HAL Id: hal-03165119 \\ https://hal.science/hal-03165119}

Submitted on 17 Mar 2021

HAL is a multi-disciplinary open access archive for the deposit and dissemination of scientific research documents, whether they are published or not. The documents may come from teaching and research institutions in France or abroad, or from public or private research centers.
L'archive ouverte pluridisciplinaire HAL, est destinée au dépôt et à la diffusion de documents scientifiques de niveau recherche, publiés ou non, émanant des établissements d'enseignement et de recherche français ou étrangers, des laboratoires publics ou privés. 


\title{
Modeling of an Ultrasonic Powder Transportation System
}

\author{
Razvan Chitic, Frédéric Giraud, Betty Lemaire-Semail \\ Univ Lille Nord de France, F-59000 Lille, France \\ Laboratory of Electrical Engineering and Power Electronics, France \\ Email: constantin.chitic@ed.univ-lille1.fr \\ frederic.giraud@univ-lille1.fr \\ www.univ-lille1.fr/l2ep \\ Richard Béarée \\ Arts et Metiers ParisTech, 59046, Lille, France \\ Email: richard.bearee@ensam.eu \\ www.ensam.fr \\ Monique Favre, Pascal Tierce \\ SinapTec, 59260, Lezennes, France \\ Email: mfavre@ sinaptec.fr \\ www.sinaptec.fr \\ Jacky Jehanno \\ AREVA, 30200, Chusclan, France \\ Email: jacky.jehanno@melox.fr \\ www.areva.com
}

\section{Keywords}

«Friction control», «powder transportation», «ultrasound», «vibrations»

\begin{abstract}
This paper presents a new powder transportation system that uses a high frequency flexural stationary wave coupled with a low frequency horizontal displacement of a beam to produce the transport of the powder. The ultrasonic wave is produced with the help of piezoelectric cells glued under the beam and is used to decrease the friction coefficient between the powder and the beam surface.
\end{abstract}

\section{Introduction}

Powder transportation systems can convey powder amount over long distances, but add no value to the product in an industrial process. These systems often use conveyor belts or vibratory conveyors which are often noisy mechanical systems, requiring a massive energy consumption and costly maintenance due to their moving parts. The Ultrasonic Powder Transport Systems use ultrasonic vibrations to transport powder. For example, in [1] and [2], an ultrasonic progressive wave propagates into a specific pipe material with appropriate absorption properties. So a simple device is designed with no moving part, which can transport powder with good performances. However, the pipe material needs to absorb the reflective wave, dissipating the electrical power into heat. In this paper, we use a high frequency flexural stationary wave coupled with a low frequency horizontal displacement. This principle already demonstrated its capability to convey powder at reasonable speed. The aim of the paper is to focus on the modeling of this device. 


\section{Presentation of the system}

The system is built up with a steel ruler animated with a low frequency horizontal movement (LFM). If alone, this movement doesn't produce any powder transportation. This is why, piezoelectric cells are glued on the ruler in order to produce a High Frequency Vibration (HFV), by synchronizing HFV on LFM, we can produce the powder transportation. The figure 1 shows the experimental test setup, and the connections between each component. The figure 2 shows the high frequency deformation of the ruler when HFV is switched on.

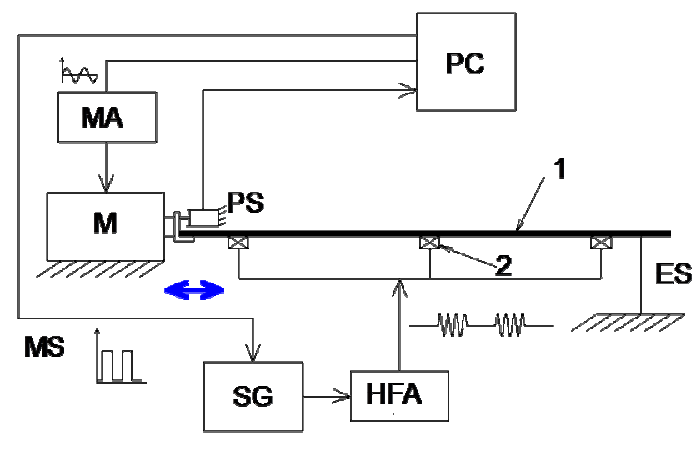

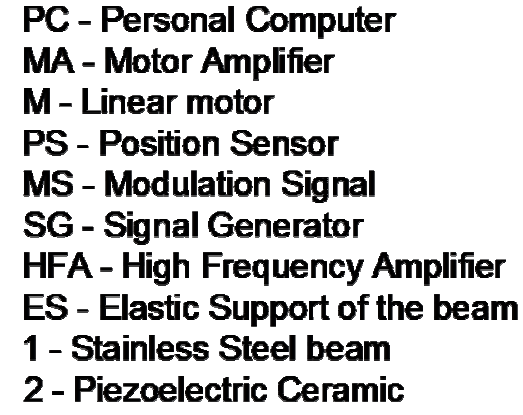

Fig. 1: Experimental test setup

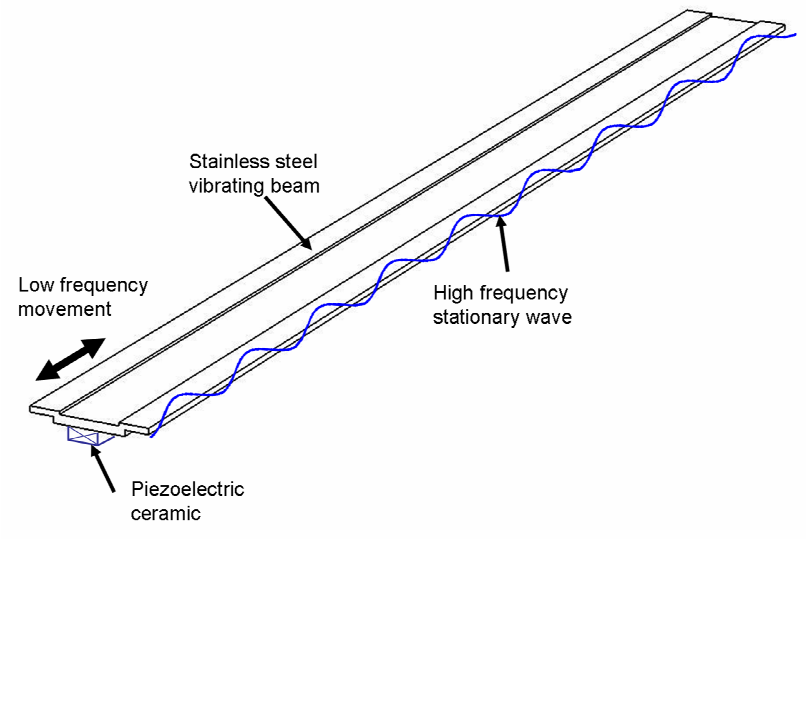

Fig. 2: The High Frequency Deformation of the Ruler

The system works as follows. Powder is deposited on the ruler. Then the linear motor (M) is switched on, producing the LFM. Position of the ruler is measured by a linear position sensor PS. Typical movement produced are oscillations at $1 \mathrm{~mm}$ of amplitude and $25 \mathrm{~Hz}$. According to ruler's position, the High Frequency Amplifier (HFA) is switched ON or OFF. It supplies piezo-cells with an alternative voltage at fixed frequency (around $25 \mathrm{kHz}$ ) and variable amplitude ( 0 when HFA is OFF, 200V when HFA is ON). When energized, the piezo-cells produce a stationary wave in the ruler. Its amplitude is about $1 \mu \mathrm{m}$, and the wavelength is $25 \mathrm{~mm}$. Under those high frequency vibrations, the powder is shacked, and lifted up, producing a friction reduction, [3] [4] between the ruler and the powder. Hence, in such contact conditions, the powder can move relatively to the ruler.

Performances of the powder transportation depend on the time when HFV is switched on or off. It's in order to determine this moment, that a modeling is introduced, and detailed in next section of this paper. 


\section{Modeling of the Ultrasonic Transportation System}

\section{Effect of the ultrasonic vibrations}

Ultrasonic vibrations have several effects on powder, leading to several applications in industry. In this paper, we focus on the friction reduction between the vibrating plate and the powder. To illustrate this point, we inclined the plate, and we put powder on it. Without vibration, the powder stays on the plate, due to friction between powder and the plate. When ultrasonic vibrations are switched on, then the friction decreases, and the powder slips on the vibrating plate almost without inclination of the beam. We then measure the flowing rate of the powder. In this try, there is no LFM, powder is transported only by gravity.

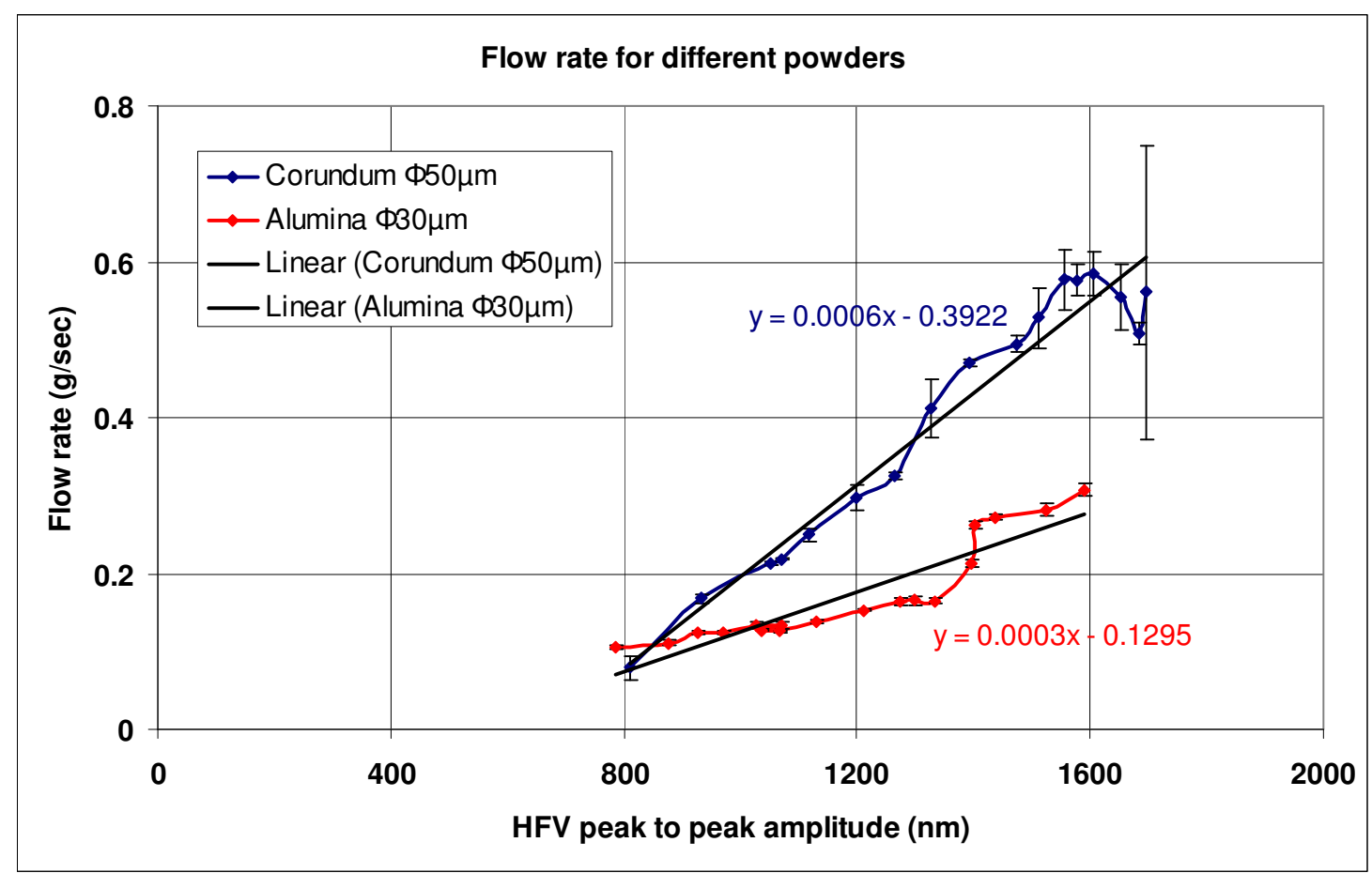

Fig. 3: Powder flow rate for an inclination of $15^{\circ}$

As it can be seen, the larger the vibration amplitude is, the lower friction is obtained. However, the behavior depends on powder properties. For example, Alumina has lower friction reduction than Corundum for the same vibration amplitude.

In this paper, we make the assumption that friction has a static behavior, and also depends on powder's speed. We will write:

$$
F_{f}=F_{0}+f_{v} \frac{d x}{d t}
$$

where $F_{f}$ is the global friction force, $F_{0}$ is a static friction force, $f_{v}$ is a viscous friction coefficient, and $d x / d t$ is the powder's speed. Given the results of figure $3, \mathrm{~F}_{0}$ and $\mathrm{f}_{\mathrm{v}}$ both depend on $\mathrm{W}$, the amplitude of the HFV. 


\section{Modeling behavior}

In the final paper, we describe the dynamic behavior modeling of the powder. For that purpose, we assume that the powder stays compact, and can be considered as a solid material [5] [6]. We then consider two separate states:

- The powder slides on the plate is state $S 1$, and the force $F_{f}$ acts on it,

- The powder is static on the plate is state S2.

Coulomb's friction law is then laid down on this system: powder changes from state S1 to state S2 when its speed relatively to the plate is null; plate changes from state $S 2$ to S1 when the force of the plate on the powder is above a threshold namely $\mathrm{F}_{\mathrm{s}}$. This behavior can be summarized by the chart of figure 4 .

Fig. 4: The two states of the powder

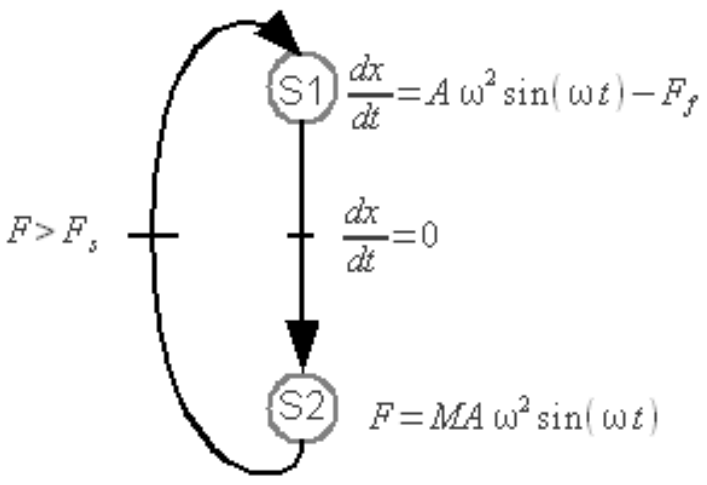

On a dynamical point of view, there are only 2 forces applied to the powder, which are the force of the plate on the powder and gravity. In our case, we are only interested on the tangential behavior of the powder. Moreover, since $d x / d t$ represents the speed of the powder in the tangential axis, and measured in a moving frame attached to the vibrating plate, we obtained equation (2) to calculate the powder's speed:

$$
M \frac{d^{2} x}{d t^{2}}=M A \omega^{2} \sin (\omega t)-F-P \sin (\alpha)
$$

where $M$ is the powder's mass, $A$ is the LFM 's amplitude, $\omega$ is the LFM's pulsation and $\alpha$ is the inclination of the beam.

In state $\mathrm{S} 2$, the powder doesn't move, so $d x / d t=0: \mathrm{F}$ is calculated consequently.

Finally, to take into account HFV, we have two sets of parameters $\left(\mathrm{F}_{0}, \mathrm{f}_{\mathrm{v}}\right.$ and $\left.\mathrm{F}_{\mathrm{s}}\right)$ which are used according to HFV state. To improve the quality of the simulation results, we have tried to measure these parameters by using our test bench. We have measured only the static friction coefficient for the corundum powder in the two cases with HFV ON and with HFV OFF. The coefficients were determined by measuring the angle of beam inclination needed for starting the slipping of the powder on the ruler. The values are presented in the table I.

\section{Table I: Static friction coefficients for HFV ON and OFF}

\begin{tabular}{|c|c|}
\hline \multicolumn{2}{|c|}{ Corundum } \\
\hline HFV OFF & HFV ON \\
\hline 0.84 & 0.14 \\
\hline
\end{tabular}

We can see that, by applying the ultrasonic vibration, the friction coefficient diminish quickly. 
Knowing the static friction coefficients, noted $\mu_{\mathrm{s}}$, and the gravitational acceleration $\mathrm{g}$, we can calculate the threshold $\mathrm{F}_{\mathrm{s}}$ using the equation:

$$
F_{s}=\mu_{s} M g
$$

Due to the difficulty of measurement, the viscous friction coefficient was imposed in an arbitrary manner.

\section{Dynamic behavior of the corundum powder}
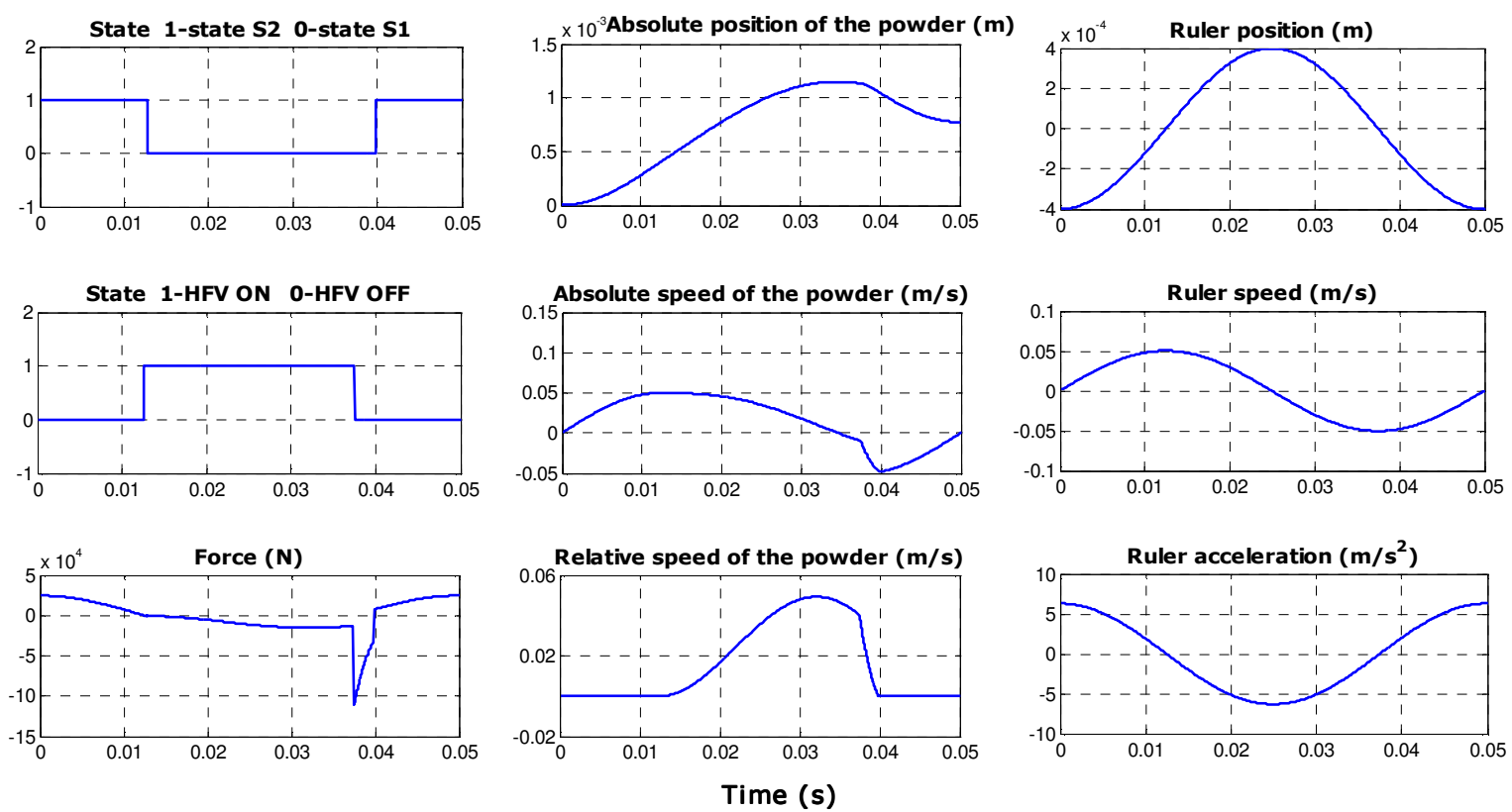

Fig. 5: Dynamic behavior of the corundum powder

The results of the figure 5 show the dynamic of the powder calculated on a LFM period. It shows that the speed of the powder measured in the moving reference frame affixed to the plate is not constant. It equals 0 when the powder is in state S2. When HFV are switched on, the powder starts sliding on the plate (at $\mathrm{t}=0.012 \mathrm{sec}$ ). When HFV are switched off (at $\mathrm{t}=0.038$ ), the powder breaks until $d x / d t=0$. Hence, ultrasonic vibrations produce an asymmetry in contact conditions, which lead to a powder transportation. The dynamic modeling we developed helps to highlight and understand this phenomenon.

The use of ultrasound is visible if a comparison between the curve of the absolute velocity of the powder and the speed of the bar is made. It is observed that, at the beginning of the transport cycle, whereas the HFV is OFF, the powder follows the movement of the ruler; then, when HFV is ON, the velocity of the powder follows a different path from that of the bar, which takes up about $0.04 \mathrm{~s}$. But, at $0.025 \mathrm{~s}$ the ruler changes the direction of movement, which does not affect the movement of the powder, thanks to the ultrasonic vibration and also to the kinetic energy that it has accumulated.

This simulation allows us to better analyze the influence of the HFV on transport and also to justify the moments when the HFV is activated relative to LFM movement of the ruler.

We can then calculate the average speed of the powder relatively to the plate, and compare the simulation to the measurements. As many parameters are unknown, the approach needs an identification step so as to adapt the value of the parameters of equation (1) until simulation and experiment matches as we can see in figure 6. Therefore, to match the two models, we have modified the values of the viscous friction coefficient for the two states: with and without HFV. 


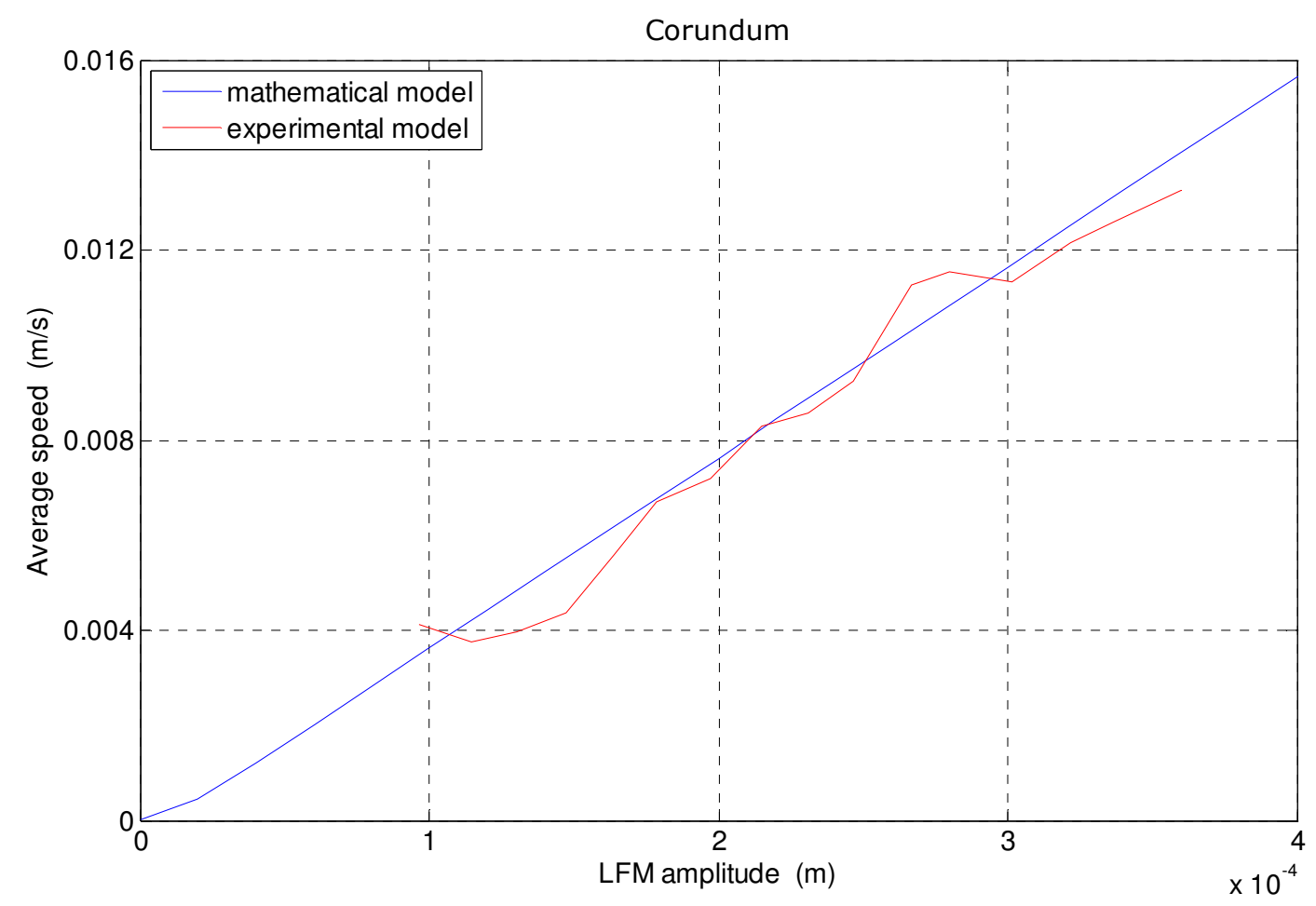

Fig. 6: Comparison simulation-experiment

\section{Conclusion}

In this work, a system of powder transportation is described. It uses a low frequency oscillation movement combined with ultrasonic vibration synchronized on the plate's position. We propose a modeling which allows us to calculate the average speed of the powder in the plate's reference frame. Simulation results are compared to measurements and both are consistent.

Future work will focus on the comparison of the system with a more conventional powder transportation system which uses low frequency movements only, in terms of efficiency, reliability and cost.

\section{References}

[1] M. Mracek and J. Wallaschek, "A system for powder transport based on piezoelectrically excited ultrasonic progressive waves," Materials Chemistry and Physics, vol. 90, no. 2-3, pp. 378-380, avril 2005.

[2] U. Kühne and U. Fritsching, "Dosage of highly disperse powders by ultrasound agitated tube modules," Powder Technology, vol. 155, no. 2, pp. 117-124, juillet 2005.

[3] M. Biet, F. Giraud, and B. Lemaire-Semail, "Squeeze film effect for the design of an ultrasonic tactile plate," IEEE Trans. Ultrason., Ferroelect., Freq. Contr., vol. 57, no. 12, pp. 2678-2688, Dec. 2007.

[4] E. C. Chubb, J. E. Colgate, and M. A. Peshkin, "ShiverPad: A device capable of controlling shear force on a bare finger," presented at the EuroHaptics Conference, 2009, Salt Lake City, UT, USA, 2009, pp. 18-23.

[5] H. E. Hor and S. J. Linz, "Model for transport of granular matter on an annular vibratory conveyor," Journal of Statistical Mechanics: Theory and Experiment, vol. 2005, no. 02, p. L02005, Feb. 2005.

[6] E. M. Sloot and N. P. Kruyt, "Theoretical and experimental study of the transport of granular materials by inclined vibratory conveyors," Powder Technology, vol. 87, no. 3, pp. 203-210, Jun. 1996. 